\title{
Editorial: Women in Science: Materials
}

\begin{abstract}
Maria Chiara Bignozzi ${ }^{1 *}$, Jacqueline Anne Johnson ${ }^{2 *}$, Patricia Krawczak ${ }^{3 *}$, Emilia Morallon ${ }^{4 *}$ and Ming $\mathrm{Xu}^{5 *}$

${ }^{1}$ Department of Civil, Chemical, Environmental and Materials Engineering, University of Bologna, Bologna, Italy, ${ }^{2}$ University of Tennessee, Space Institute, Tullahoma, TN, United States, ${ }^{3}$ IMT Lille Douai, Institut Mines-Télécom, Univ. Lille, Centre for Materials and Processes, Douai, France, ${ }^{4}$ Physical Chemistry Department, Institute of Materials Science, University of Alicante, Alicante, Spain, ${ }^{5}$ School of Materials Science and Engineering, Huazhong University of Science and Technology, Wuhan, China
\end{abstract}

Keywords: women in STEM, women in science and engineering, materials engineering, materials science, gender equality

\section{Editorial on the Research Topic}

\section{OPEN ACCESS}

Edited and reviewed by: Alberto Corigliano,

Politecnico di Milano, Italy

*Correspondence:

Maria Chiara Bignozzi maria.bignozzi@unibo.it Jacqueline Anne Johnson jjohnson@utsi.edu Patricia Krawczak patricia.krawczak@imt-lille-douai.fr Emilia Morallon morallon@ua.es Ming Xu

ming.xu@hust.edu.cn

Specialty section: This article was submitted to Mechanics of Materials, a section of the journal Frontiers in Materials

Received: 15 February 2021 Accepted: 25 February 2021 Published: 23 April 2021

Citation:

Bignozzi MC, Johnson JA, Krawczak P, Morallon E and Xu M (2021) Editorial: Women in Science: Materials. Front. Mater. 8:668092. doi: 10.3389/fmats.2021.668092

\section{Women in Science: Materials}

According to UNESCO Institute for Statistics (UIS) data (2019), <30\% of researchers worldwide are women. Long-standing biases and gender stereotypes are discouraging girls and women away from science-related fields. In particular, STEM (science, technology, engineering, and mathematics) research is traditionally male dominated and women remain underrepresented. As UNESCO has highlighted, both science and gender equality are, however, essential to ensuring sustainable development. To change traditional mindsets, gender equality must be promoted, stereotypes defeated, and girls and women should be encouraged to pursue careers in STEM.

Throughout history, the contributions of female researchers to scientific progress have been extremely important. Yet, whereas the extraordinarily talented Nobel laureate Marie Skłodowska-Curie is often mentioned as a role model, it is nowadays well-established that countless women such as Lise Meitner have received less recognition and acknowledgment for their research findings than their male counterparts [so-called Matilda effect (Rossiter, 1993)].

Also, women traditionally publish less than men according to the European Commission She Figures, the ratio of women to men among authors of scientific publications in the EU being on the average one to two (European Union, 2019), and recent surveys are highlighting a further drop in academic submissions from female scientists since the start of the Covid-19 pandemic early 2020.

Role models are definitely extremely important to show to younger generations the growing impact of female researchers to science. Therefore, continuing the spirit of the International Day of Women and Girls in Science, Frontiers in Materials is proud to offer this platform to promote the work of female scientists across the breadth of materials science and engineering.

This inaugural "Women in Science: Materials" collection (Figure 1) aims to highlight the impact of women researchers working in materials science and engineering. It gathers a selection of original articles with the lead author and/or corresponding author being a woman.

A total of 32 contributions (three reviews, one brief research report, and 28 original research articles) present advances in theory, experiment, and methodology with applications to compelling problems, across almost all sections of the journal: 


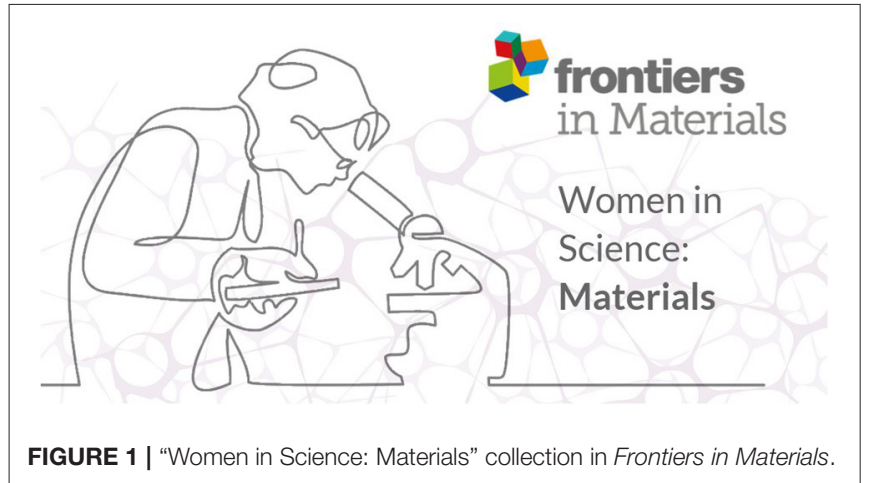

- Mechanics of materials (Bouquerel et al.; Jeong et al., TerMaath et al.; Zhu et al.)

- Smart materials (Duc et al.)

- Polymeric and composite materials (Badji et al.; Berzin et al.; Brunella et al.; Hostettler et al.; Martins and Gil; Mirbaha et al.; Padhan et al.; Quintana et al., Raj et al.; Saffar et al.)

\section{REFERENCES}

European Union (2019). European Commission She Figures 2018. Publications Office of the European Union, Luxembourg. doi: $10.2777 / 936$

Rossiter, M.W. (1993). The Matthew Matilda effect in science. Soc. Stud. Sci. 23, 325-341. doi: 10.1177/0306312930230 02004

UNESCO Institute for Statistics (2019). Women in Science ( $\left.n^{\circ} 55\right)$ [Fact sheet], UIS/FS/2019/SCI/55, UIS Publ., Montreal, QC, Canada. Available online at: https://unesdoc.unesco.org/ark:/48223/pf0000370742
- Carbon-based materials (Kato et al.; Moulefera et al.; Xu et al., Zhang et al.)

- Structural materials (Bonoli et al.; Boyer et al.; Korat and Ducman; Manzi et al., Masi et al.)

- Colloidal materials and interfaces (Garcia-Hernando et al.; Pucci et al.)

- Energy materials (Castro-Gutiérrez et al.)

- Ceramics and glass (Giosuè et al.)

- Environmental materials (Bassi et al.)

- Biomaterials (Criado-Gonzalez et al.; Kebaili et al.)

The Guest Editorial team hope that this collection of papers will be the foundation of an international network of women researchers working in materials science and engineering, and a starting point for future collaborations and discussions.

\section{AUTHOR CONTRIBUTIONS}

This Editorial was jointly written by all co-authors who also served as Guest Editors for the Research Topic. All authors contributed to the article and approved the submitted version.

Conflict of Interest: The authors declare that the research was conducted in the absence of any commercial or financial relationships that could be construed as a potential conflict of interest.

Copyright (๑) 2021 Bignozzi, Johnson, Krawczak, Morallon and Xu. This is an openaccess article distributed under the terms of the Creative Commons Attribution License (CC BY). The use, distribution or reproduction in other forums is permitted, provided the original author $(s)$ and the copyright owner(s) are credited and that the original publication in this journal is cited, in accordance with accepted academic practice. No use, distribution or reproduction is permitted which does not comply with these terms. 